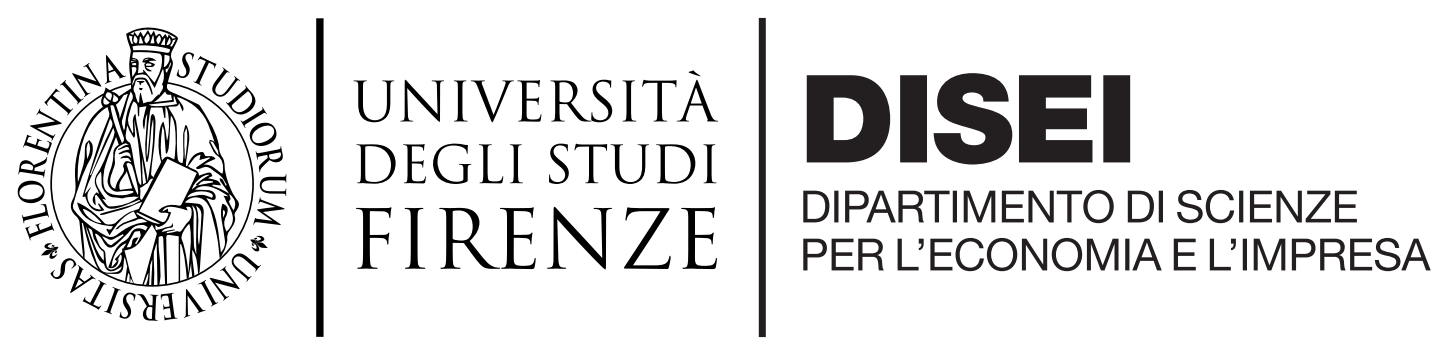

WORKING PAPERS - ECONOMICS

\title{
Budget rules with a public debt reduction target
}

\author{
Alessandro Petretto
}

Working PAPER N. 33/2019 


\title{
Budget rules with a public debt reduction target ${ }^{1}$
}

\author{
Alessandro Petretto \\ Professor emeritus \\ University of Florence \\ December 2019
}

\section{Introduction}

A budget rule establishes long-term limits to fiscal policy by means of quantitative constraints to balance aggregates, with the main aim of containing public debt or its expansion. According to IMF, in 2015, national and international rules were active in 93 countries, leading those of Euro area (EA). Budget rules can be linked to deficit, to public debt or to public expenditures; they can be fixed in nominal terms (absolute limits to financial deficit, primary deficit or current deficit of public administrations), in real terms (mainly for reference to dynamics of public expenditure) and in structural terms (surplus corrected by the cycle). The rules can be applied ex ante (for the budget subject to vote) or ex post (with reference to displayed results). They can be approved by assemblies of central or regional public administrations or according to international treaties, as in EA. Generally, they are more frequent in federal countries, in states with a consolidate democracy and political stability and open to international financial exchanges.

Budget rules try to correct the consequences of political processes enhancing public-makers to much spending and leaving deficits to increase. This usually happens in the electoral cycle, when the politicians in charges are induced, near to the electoral vote, to finance in deficit excessive measures for sustaining the economy, trusting on the information asymmetry or irrationality of voting citizen.

Other dysfunctions derive by electoral competition between two parties or coalitions: The divergence among them on public expenditure allocation induces those in command to spend a lot on own priorities, giving for granted that, in case of political change, the other party or coalition will recognize to these only a limited share or none of resources. In case of countries union, budget rules tend also to correct the lack of coordination needed for internalizing the external costs of budget deficits to other members, disregarded by national governments. Finally, budget rules try to bind the present generations to transfer the financing of expenditures whose benefits advantage them, to the non-voting future generations.

\footnotetext{
${ }^{1}$ I would like to thank the components of the group named "Dorsale: Sovranità e Debito Pubblico" de Il Mulino ed., Bologna, coordinated by Carlo Galli, where this work has been presented and discussed.
} 
The budget rules for EA countries, as well known, are three ${ }^{2}$ : a) a rule specifying a medium term objective (MTO) for the structural budget, i.e. corrected by the cycle; b) a rule for an annual reduction of the public debt level for approaching the benchmark of $60 \%$ of debt/GDP; c) a rule controlling the dynamics of real public expenditure.

About the efficacy of these rules, there is a profound debate, both in economic and political terms. Looking at the effects on deficit and debt in EA countries, with respect for instance to U.S.A and Japan, the evaluation must be moderately positive, especially during the financial crisis of sovereign debts. In 2012, the deficit on GDP in EA was of 3,8\%, with 18 countries over the bound of 3\% established by Maastricht Treaty, while in U.S.A was around 9\%, and Japan around 8\%. At the end of the crisis, in 2017, EA deficit on GDP decreases to $1 \%$, with only a member state deviating from the Maastricht constraint, while in U.S.A. it was still over $4 \%$ and in Japan a little down.

Less worth are instead the effects of the rules on public debt/GDP evolution in EA. In 2012, in the 19 countries, it was almost $92 \%$ and in 2017, it was only at $89 \%$, with three countries over $120 \%$ e some over 80\%. In 2018, 5 countries (France, Italy, Spain, Portugal and Belgium) still show high level of debt on GDP and structural deficits. The economic cycle has for sure influenced this evolution. In the same years EA moves from a recession in 2012 (-0,9\% of GDP) to an expansion on 2017 (+2,4\% of GDP), while U.S.A. and Japan are in a constant growth. In conclusion, the EA budget rules, even if necessaries had often pro-cyclical effects [Buti 2018, Buti et al. 2018].

In this note, in section two, we analyze formally the new fiscal rule for Euro area recently proposed by, among others, the European Fiscal Board [EFB, Annual Report, 2018], based on an expenditure rule with a debt reduction target. Then, we compare it with the actually in charge MTO rule, based on the structural budget and the so-called Golden rule (GR), traditionally attributed to Richard Musgrave [Musgrave and Musgrave 1976, Ch. 28], and often evoked by the criticists of the former rule. In section three, we consider how the three rules work for controlling the dynamic of public debt level in terms of GDP. Fourth section concludes stressing the superiority for several reasons of ER over MTO and GR too.

\section{A unique instrument of fiscal discipline: the Expenditure Rule with a debt target}

\footnotetext{
${ }^{2}$ The legal structure of fiscal discipline in EA is recalled by six laws (the s.c. six pack), approved by European institutions in November 2011; the Fiscal Compact, i.e. the Treaty on stability, coordination and governance in Economic and monetary Union, ratified by member states in 2012; and two further regulatory acts (n.472 and 473, May 2013, the so-called Two pack).
} 


\subsection{The EFB new rule: A simple one and based on observables figures}

In principle, fiscal rules should be transparent and quite simple, being based on a set of tasks monitored by means of indexes known by the government. They should allow, at the same time, counter-cyclical and stabilizing fiscal measures, create incentives to public debt reduction, and permit a way out clause in case of wide macroeconomic shocks. Recent studies have shown that rules based on nominal public expenditure growth, in coherence with a public debt reduction within a specific range, satisfy these features better than the current more complex system, which being based on unobservable variables, as the output gap, may create many disputes.

A specific Expenditure rule (ER), bringing also a debt reduction target, has been proposed by European Fiscal Board [EFP, 2018, Beetsma et al. 2018]. According to this, for every EA country, at time $t$, the following formula must be fulfilled ${ }^{3}$ :

$$
\hat{e}_{G, t}=g^{p}+E_{t-1} \pi_{t}-\gamma_{t}\left(b_{t}-b^{*}\right)
$$

where $\hat{e}_{G, t}$ is the rate of growth of nominal expenditure configuration allowed by the rule; $g^{p}$ is the rate of real potential GDP growth. $E_{t-1} \pi_{t}$ is the expected inflation, so $n_{t}^{p}=g^{p}+E_{t-1} \pi_{t}$ is the nominal rate of potential growth, which differs from the nominal actual one $n_{t}=g+E_{t-1} \pi_{t} ; \gamma_{t}$ is the speedy parameter of convergence to the target debt/GDP, with $0<\gamma_{t}<1$; finally, $\left(b_{t}-b^{*}\right)$ is the difference between current debt/GDP ratio and the target (namely 60\%).

Public expenditure is net of interests' payments, expenditure for unemployment, and net of the expected impact of any discretional changes on the revenue (i.e. reforms of fiscal basis and rates). Finally, the rule allows a share of agreed public investments to be deducted. The two first adjustments tend to explicit the counter-cyclicity of the ER, but by excluding also the effect of structural measures on public expenditure. Actually, the simulations by Darvas et. al (2018b) for the France, show that the rule has good counter-cyclical properties facing unexpected demand shocks. The last adjustment tends to avoid manipulations of fiscal rules, e.g. pre-electoral cuts, not compensated by expenditure contraction. It consents also to the elected governments to make budget choices reflecting their fiscal preferences.

As said, public investments reductions from the regulated expenditure can be obtained by an agreement with the EC in a three years plan, bringing in the budget reduction shares of expenditure yearly imputed. This commitment to reduce from the benchmark expenditures the public investments

\footnotetext{
${ }^{3}$ See for instance Debrun et al. 2018, Darvas et al. 2018. Such a proposal has been inserted in the proposals package by the so called 7+ 7 Report (2018), discussed and commentated by 25 contributions, collected, from April to August 2018 by Vox EU [Pisani-Ferry 2018]. Feld et al. (2018) have proposed a combination of ER and MTO rule.
} 
should have a more systematic feature than the simple margins of flexibility, to day recognized by EC as a premium for "good conduct".

Of course, the crucial parameter of ER is the "convergence speed" $\gamma_{t}$. As regard, a sole parameter for all countries does not provide sustainable fiscal policies for those with a large distance to the reference level of debt/GDP ratio. It is preferable a specific procedure agreed with the EC. According to the proponents of ER, two independent institutions - the European Fiscal Council (EFC), and for each EA member, a National Fiscal Council (NFC) - should be created for developing the agreements required by the rule [Darvas et al. 2018a, b].

Each year the government of a member state proposes a medium term objective ( 3 years) of debt/GDP reduction, to be inserted in the annual Stability Program for the EC. Both EFC and NFC are consulted for providing an evaluation of the objective in terms of feasibility and ambition. Then a discussion is open at EC level on the basis of the following procedures and parameters:

- The gap between the current debt/GDP and the long term task (e.g. 60\%): a large gap requires a more ambitious adjustment;

- A wide analysis on fiscal sustainability, giving a particular credit to the countries that are doing structural reforms favoring the growth of potential GDP;

- An analysis of the economic situation and of the path of debt reduction.

The Commission presents own conclusions on the reduction debt target for each state to the European Council, which can vote against only with a qualified majority. The NFC prepares a medium term growth projection of nominal GDP, based on the potential one, the expected inflation and a possible cyclical correction, when initial conditions strongly differ from the long run equilibrium. Given the debt reduction objective, the NCF provides a consistent growth path of nominal public expenditure and uses it for defining an upper bound for the successive year, $\hat{e}_{G t}$, to be used for preparing the annual budget.

The main advantage of such a rule are that it is based on observables figures, and not estimated ones, in particular it does not require, as with MTO rule, the output gap calcolation. Moreover, it admits an adaptive fiscal policy, i.e. counter cyclical, both because revenue changes do not influence the ER index and this allow to keeping a virtuous behavior during the positive phase of the cycle. Finally, the rule does not oblige to public expenditure reductions for compensating fiscal burden reductions during the negative phase of the cycle.

\footnotetext{
${ }^{4}$ As the estimations on the structural budget have been in these years subjected to significant revisions, because of the uncertain calculation of the output gap, one could think that also the estimation of the rate of potential GDP growth on the medium term, at the basis of ER, will be itself subjected to many revisions. Claeys et al. (2016) have instead shown that this was not the case.
} 


\subsection{Expenditure rule and Golden rule: similarities and differences}

The most interesting feature of ER is the agreed amount of public investments in detraction to the expenditure growth index. This allows extracting by the fiscal discipline meaningful interventions aimed at increasing the material and immaterial stock of public capital, and then to increase the potential growth of the economy. In this respect, often the economic literature refers to the so-called Golden Rule (GR), due to Peggy and Richard Musgrave (1976), which allows an explicit favorable treatment to public investments, not conditioned to occasional concessions of flexibility margins.

With the GR, the deficit on GDP $h_{t}$ is composed in three parts: the current budget, $c_{G, t}$, the depreciation of P.A. stock of capital, $a_{t}$, and the net public investments, $i_{G, t}$, all on GDP:

$$
h_{t}=c_{G, t}+a_{t}+i_{G, t}
$$

According to the actual rules, the deficit is divided in structural and cyclical one ${ }^{5}, h_{t}=h_{t}^{s}+h_{t}^{c}$. Therefore, by supposing the MTO rule requires $-h_{t}^{s}=\mu_{t} \geq 0$, i.e. a non-negative structural budget, the allowed budget (total deficit or surplus), on GDP is

$$
\hat{h}_{t}^{M T O}=-\mu_{t}+h_{t}^{c}
$$

With the GR, instead, it would be:

a) a current balanced budget

$$
c_{G, t}+a_{t}=0
$$

b) an allowed deficit in capital terms

$$
\hat{h}_{t}^{G R}=i_{G, t} \geq 0 \text {. }
$$

In words, the corresponding objective, in terms of budget, would require the equilibrium of current balance, comprehensive of the expenditures for re-building the public capital stock, and an allowed deficit due to net public investments, independently by the cyclical phase. Notice that, with ER, instead the allowed policy refers to a growth of public investments per year, not the level of them as in [5]. The basic idea of GR originates by firm economics theory: If the net return of an investment project is over the cost of debt, the investment justifies the recourse to debt itself. Actually, at firm level, if the asset is profitable, the enterprise value increases, but in the whole system, the economic policy cannot be interested at the accumulation of an asset value. Hence, in full employment, the

\footnotetext{
${ }^{5}$ The cyclical deficit in absolute terms is linked to the cycle, being equal to is $-\varepsilon O G_{t}$, where $\varepsilon$ is the sensitivity of budget to output gap, OG, i.e. the difference between actual and potential GDP, in logarithmic terms: $\ln Y_{t}$ $=y_{t}$ and $\ln Y^{p}=y^{p}$.
} 
financing by debt of public investments is admitted whenever the project gives up a present value of intertemporal flows of increased fiscal revenues, due to the income produced by the activities using the infrastructures, higher or equal to the initial expenditure. However, it would appear reasoning that each generation should pay for the use of public services; hence, allocative efficiency implies taxes should cover the entire loss of value of the stock of social capital, leaving only the expenditure for the increase of stock to debt financing.

Notice that

$$
i_{G t}=h_{t}^{c}, \quad \mu_{t}=0 \rightarrow \hat{h}_{t}^{M T O}=\hat{h}_{t}^{G R}
$$

i.e. with a zero structural budget the deficit admitted is the same by the two rules if the cyclical deficit is fully devoted to net public investments.

A limit of an automatic accountable rule as GR is the difficult distinction between capital and current expenditures, which apart the possible manipulations (like those for the estimations of depreciation), does not take into account current public expenditures enhancing potential growth by improving human capital stock (education, health care) and financing R\&D. This occurrence is avoidable by a three years plan agreed with EC selecting the expenditures items to be subtracted from the ER index. Hence, ER would be a more flexible rule than GR.

\section{MTO, ER and GR: the impact on the public debt dynamics.}

\subsection{The debt reduction target on the rules formulas}

Let us consider an EA member that, at time $t$, is running a recessive cyclic phase (negative output gap) and the following public debt state:

$$
\begin{aligned}
& b_{t-i}=\bar{b} ;\left(\bar{b}-b^{*}\right)>0 \\
& b_{t}=\frac{1+r_{t}}{1+n_{t}} \bar{b}+d_{t}
\end{aligned}
$$

where $r_{t}$ is the nominal rate of interest, $r_{t} \bar{b}$ the interests payment on GDP and $d_{t}$ is the primary deficit ratio on GDP. As $\frac{1+r_{t}}{1+n_{t}} \approx 1+r_{t}-n_{t}$, we may get a basic formula of debt dynamics as follows:

$$
\Delta b_{t} \equiv b_{t}-\bar{b}=h_{t}-n_{t} \bar{b}
$$


Let us suppose a $T$ years objective of debt/GNP annual reduction of $\varphi_{t}<0, t=1, \ldots T$, and let us explicit how the previous fiscal rules can achieve it.

According to the MTO Rule, with structural budget at time $\mathrm{t}, \mu_{t} \geq 0, t=1, . . T$, we have, given [3], as follows:

$$
\Delta b_{t}=-\mu_{t}+h_{t}^{c}-n_{t} \bar{b}=\hat{h}_{t}^{M T O}-n_{t} \bar{b}
$$

Thus for achieving the target $\Delta b_{t}=\varphi_{t}<0$, by [6b] it must be $\frac{\hat{h}_{t}^{\text {MTO }}}{n_{t}}<\bar{b}$.

As a consequence, a policy of consolidation of debt level, in a negative cyclical phase with a low nominal potential GDP rate of growth, could be pursued only if an appropriate MTO is chosen, i.e.:

$$
\mu_{t}^{*}=n_{t} \bar{b}+h_{t}^{c}-\varphi_{t},
$$

It is highly probable that this fiscal discipline (with $\mu_{t}>0$ ) creates up a pro-cyclical Fiscal stance ${ }^{6}$.

According to ER we have, by [1] as follows

$$
\hat{e}_{G, t}=n_{t}^{p}-\gamma_{t}\left[\Delta b_{t}+\left(\bar{b}-b^{*}\right)\right]
$$

Thus for achieving at time $t$ the target $\Delta b_{t}=\varphi_{t}<0$, a country, with a level of debt at time $t-1$ far from the benchmark $b^{*}$, must plan a profile of public expenditure lower than the nominal potential GDP rate of growth:

$$
\hat{e}_{G, t}-n_{t}^{p}=-\gamma_{t}\left[\varphi_{t}+\left(\bar{b}-b^{*}\right)\right]<0 ; .
$$

Notice that now, by this rule, no link to the cyclical phase is considered. In the special case, where the rule would require a uniform decay of public debt ratio, such that $\varphi_{t}=\varphi^{T}=-\gamma^{T}\left(\bar{b}-b^{*}\right)$, we have

$$
\hat{e}_{G, t}^{*}=n_{t}^{p}-\left(\varphi^{T}-\frac{\varphi^{T}}{\gamma^{T}}\right) \gamma^{T}=n_{t}^{p}+\left(1-\gamma^{T}\right) \varphi^{T}
$$

Notice how the convergence speedy and the annual decay are linked to the duration of consolidation plan, $T$. Actually, we have $T \varphi^{T}=\bar{b}-b^{*}, \quad$ and $\gamma^{T}=\frac{1}{T}$.

\footnotetext{
${ }^{6}$ Fiscal stance analysis is usually carried on by combining two indexes: a) the ratio between structural primary budget changes and potential GDP; $b$ ) the ratio between the output gap and the potential GDP. The first one provides an empirical measure of discretional fiscal policy, the second one a measure of cycle evolution.
} 
Now considering GR, by [5] and $\Delta b_{t}=\hat{h}_{t}^{G R}-n_{t} \bar{b}$, the compatible level of net public investment at year $t$, is

$$
i_{G, t}^{*}=n_{t} \bar{b}+\varphi_{t}
$$

Consequently, we have that a planned negative dynamics of the level of public debt is guaranteed whenever it is $i_{G, t}<n_{t} \bar{b}$. Therefore, in GR too, economic policy finds a constraint to the desired public investments expenditure.

Tab.1 summarizes the fiscal measures satisfying the three budget rules.

Tab.1: Compatible fiscal policy with public debt target: reduction of debt/GDP by $\varphi_{t}$

\begin{tabular}{|l|l|l|l|}
\hline Fiscal Rules & Instrument & Formulas & Crucial economic variable \\
\hline $\begin{array}{l}\text { Structural } \\
\text { budget }\end{array}$ & MTO & $\mu_{t}^{*}=-n_{t} \bar{b}+h_{t}^{c}-\varphi_{t}$ & $\begin{array}{l}\text { Output Gap and nominal } \\
\text { GDP rate of growth }\end{array}$ \\
\hline $\begin{array}{l}\text { Expenditure } \\
\text { Rule }\end{array}$ & $\begin{array}{l}\text { Expenditure } \\
\text { benchmark profile } \\
\text { of growth }\end{array}$ & $\begin{array}{l}\hat{e}_{G, t}^{*}=n_{t}^{p}-\left[\varphi_{t}+\left(\bar{b}-b^{*}\right)\right] \gamma_{t} \\
\text { with } \varphi_{t}=\varphi^{T}=-\gamma^{T}\left(\bar{b}-b^{*}\right), \\
\hat{e}_{G, t}^{*}=n_{t}^{p}+\left(1-\frac{1}{T}\right) \varphi^{T}\end{array}$ & $\begin{array}{l}\text { Potential GDP rate of } \\
\text { growth and speedy of } \\
\text { convergence to the chosen } \\
\text { target Debt/GDP }\end{array}$ \\
\hline Golden Rule & $\begin{array}{l}\text { Net } \\
\text { investment }\end{array}$ & \begin{tabular}{l}
$i_{G, t}^{*}=n_{t} \bar{b}+\varphi_{t}$ \\
gominal GDP rate of \\
\hline
\end{tabular}
\end{tabular}

\subsection{A simple exercise of simulation}

Let us consider the emblematic case of Italy, country with high $\operatorname{debt}^{7}$ and low growth ${ }^{8}$, by looking at data by NADEF $2019^{9}$.

Tab. 2. Parameters by ITALY, NADEF 2019

\begin{tabular}{|l|l|l|l|l|l|l|l|l|}
\hline$g$ & $E \pi$ & $n$ & $n^{p}$ & $b$ & $b^{*}$ & $n b$ & $b-b^{*}$ & $h_{t}^{c}$ \\
\hline 0,006 & 0,008 & 0,014 & 0,024 & 1,325 & 0,6 & 0,019 & 0,725 & 0,008 \\
\hline
\end{tabular}

\footnotetext{
${ }^{7}$ The ratio debt/GDP has been constantly over $130 \%$ in the last ten years.

${ }^{8}$ UPB (2019) esteems for 2019 in Italy an -1,7\%.output gap (effective minus potential GDP in \% w.r.t. the latter).
}

${ }^{9}$ Nota di variazione al Documento di economia e finanza 2019. NADEF is the document the government must presented in September at the Parliament as the framework for the Budget act. 
Now suppose three scenario of a long run program for reducing the debt/GDP to the benchmark 0,6, correspondingly in 20, 30 and 40 years, with a uniform annual decline. By applying the data of Tab. 2 to the formulas in Tab. 1, we obtain that following fiscal policies for year $t=2020$, implied by the three rules.

Tab. 3 Fiscal policy at time $t$ according to MTO, ER and GR (\%)

\begin{tabular}{|l|l|l|l|}
\hline Parameters/policies tools & $\mathbf{T = 2 0}$ & $\mathbf{T}=\mathbf{3 0}$ & $\mathbf{T}=\mathbf{4 0}$ \\
Debt/GDP yearly reduction $\varphi$ & $\mathbf{- 0 , 0 3 6}$ & $\mathbf{- 0 , 0 2 4}$ & $\mathbf{- 0 , 0 1 8}$ \\
\hline MTO, $\mu_{\mathrm{t}}$ & 2,5 & 1,3 & 0,7 \\
\hline Nominal expenditure growth, $e_{G}$ & $-1,0$ & 0,1 & 0,7 \\
\hline Net public investment/GDP, $i_{G}$ & $-1,5$ & $-0,5$ & 0,1 \\
\hline
\end{tabular}

Clearly, the three rules in the two scenario of consolidation in 20 and 30 years imply pro-cyclical policies. These plans require, in non-positive phases of the cycle, a MTO with a very high structural surplus (and a nominal surplus too). ER rule becomes moderately counter-cyclical only in the 30years scenario when it requires a very low positive increase of nominal public expenditure. ER could become more counter-cyclical if the granted flow of public investment over the increase of the expenditure defined by the rule is high. Finally, in some sense surprising, it turns out that GR rule tends to be strongly pro-cyclical, requiring strong contractions of net investment or strong surplus in current budget.

In the 40-years scenario, only ER is counter-cyclical as shows a sufficient increase of public expenditure, which can be aided by the agreed investments and tax cuts, not inserted in the chosen index. MTO is still positive and GR is moderately counter-cyclical requiring a very low flow of net public investment.

Notice that the exercise considers fixed rates of growth, both in terms of potential and actual GDP, not taking into account the different effects of fiscal rules on them, even in the short term. Actually, we should expect to derive more expansive effects by ER and GR, given the more favorable to growth composition of public expenditure they imply. Given this, let us suppose we want to apply GR, establishing a net investment on GDP at time $t$ equal to 1,5\% and that measure could guarantee an increase in the nominal rate of $0,6 \%$, by bringing it to $2 \%$. Solving the following equation for $x$ we get the benchmark level $b^{T}$ we can reach at a time T:

$$
\hat{i}_{G, t}=(n+\Delta n) \bar{b}+\frac{(\bar{b}-x)}{T}=0,015 .
$$

According to the figures of Table 2, we get $x=1,08$ at $T=20, x=0,96$ at $T=30, x=0,84$ at $x=40$. Therefore in $20(30,40)$ years we could reduce the debt/GDP from 1,325 to respectively 1,08, 0,96, 
0,84: A rather unsatisfactory profile, we may say. Now, let us assume that by ER an allowed nominal rate of growth by $1 \%$, together with an increase of public investments can increase the potential rate of growth from $2,4 \%$ to $3 \%$. We can derive the debt/GDP benchmark according $\mathrm{T}=20,30$ and 40 , by the following equation:

$$
\text { [11a] } \quad \hat{e}_{G, t}^{*}=\left(n_{t}^{p}+\Delta n_{t}^{p}\right)+\left(1-\frac{1}{T}\right) \frac{(\bar{b}-x)}{T}=0,01
$$

or

[11b] $T\left[0,01-\left(n_{t}^{p}+\Delta n_{t}^{p}\right)\right]+\frac{(T-1)}{T}(\bar{b}-x)=0$.

If we take into account that $\frac{(T-1)}{T} \approx 1$, equation [11b] approximately becomes as follows:

[11c] $x=\bar{b}+T\left[0,01-\left(n_{t}^{p}+\Delta n_{t}^{p}\right)\right]$.

Thus, solving this, we get $x=0,92$ at $T=20, x=0,73$ at $T=30$, and under the benchmark of 0,6 at $T=40$ : Now an agreeable profile.

\section{Summing up}

In this note we have compared three budget rules: the structural budget at medium term (MTO), as imposed by Fiscal compact, the new expenditure rule (ER) proposed by European Fiscal Board (2018) and the Golden rule (GR), generally desired and evoked by the criticists of fiscal Compact rules. Thus, having a specific task of debt/GDP reduction, we have computed the correspondent expressions of structural budget, rate of growth of nominal net expenditures, and the net public investment.

As far as the fiscal stance is concerned, by a simple simulation exercise (with figures taken from NADEF 2019 for Italy), modeled in three scenario of timing of consolidation approaching debt/GDP by $60 \%$ - 20, 30 and 40 years - we derive that only with a plan long 40 years the three rules are counter-cyclical, although moderately. The best one appears to be ER rule.

It is important to emphasize that the exercise considers fixed rates of income growth, both in terms of potential and actual GDP, hence it does not take into account the different effects of fiscal rules on them, even in the short term. If we would like to extend the analysis in this direction, we should expect to derive more expansive effects by ER and GR, given the more favorable composition of public expenditure w.r.t. growth they imply.

For instance, we find that following a GR, with a net public investment on GDP at time t equal to $1,5 \%$ - assuring a $0,6 \%$ increase in the nominal rate of growth of, up to $2 \%$ - we would reach a Debt/GDP ratio of about $108 \%$ in 20 years and $96 \%$ in 30 years. With instead ER - according to a 
rate of growth of expenditure of $1 \%$ and a set of allowed public investments, able to generate a rate of potential GDP of 3\% - debt/GDP ratio would reach the level of about $90 \%$ in 20 years and $70 \%$ in 30 years. Thus a better profile.

\section{REFERENCES}

A. Benassy-Quéré et al., 7+7 Report (2018), Reconciling Risk sharing with Market discipline: a constructive approach, CEPR Policy Insight, n.91, January

A. Benassy-Quéré et al., 7+7 Report, 2 (2019), "Euro area architecture: What reforms are still needed, and why", VoxEU.org, May

R. Beetsma, N. Thygesen, A. Cugnesca, E. Orseau, P. Ellafotou, S. Santacroce (2018), "Reforming the EU fiscal framework: a proposal by the European Fiscal Board", VOX CEPR, Policy Portal, 26 October.

M. Buti (2018), "Fiscal rules: an assessment of recent reforms", National Conference on Public Accountancy, Pisa, 6 December 2018

M. Buti, G., Giudice e J. Leandro (2018), "Deepening EMU requires a coherent and well sequenced package", VoxEU.org, April.

G. Claeys, Z. Darvas e A. Leandro, (2016), "Proposal to revive the European fiscal framework", Bruegel Policy Contribution n.47, September.

Z. Darvas, P. Martin e X. Ragot, (2018a), European fiscal rules require a major overhaul", Le notes du conseil d'analyse économique, n. 47, September.

Z. Darvas, P. Martin e X. Ragot, (2018b), "The economic case for an expenditure rule in Europe", VOX, CEPR, Policy Portal, 12 September.

X. Debrun, L. Eyraud, A, Hodge, V. Lledo. C. Pattillo e A Senhadji, (2018), Fiscal rules: make them easy to love and hard to cheat, IMF blog.

European Fiscal Board, Annual Report, (2018).

L. Feld, C M Schmidt, I Schnabel and V Wieland (2018), "Refocusing the European fiscal framework", VoxEU.org, September.

R. Musgrave and P. Musgrave (1976), Public finance, theory and practice, McGrowth-Hill, New York, II ed.

J. Pisani-Ferry (2018), Euro area reform: an anatomy of the debate, CEPR Policy Insight, n.95, October.

Ufficio Parlamentare del Bilancio, (UPB 2019), Audizione alla Commissioni bilancio di Camera e Senato, sulla NADEF, 8 October, 2019. 